\title{
EFFECTS OF 2 PHYSICAL EXERCISE PROGRAMS (CIRCUIT TRAINING AND BRISK WALK) CARRIED OUT DURING WORKING HOURS ON MULTIDIMENSIONAL COMPONENTS OF WORKERS' HEALTH: A PILOT STUDY
}

\author{
JOSE M. SAAVEDRA ${ }^{1}$, HAFRÚN KRISTJÁNSDÓTTIR ${ }^{1}$, STEINN B. GUNNARSSON, \\ and ANTONIO GARCÍA-HERMOSO ${ }^{2,3}$
}

${ }^{1}$ Reykjavik University, Reykjavik, Iceland

School of Social Sciences, Physical Activity, Physical Education, Sport and Health (PAPESH) Research Centre, Sports Science Department

${ }^{2}$ Navarrabiomed-Public University of Navarra (UPNA), Pamplona, Spain

Health Research Institute of Navarra (IdiSNA), Navarra Hospital Complex (CHN)

${ }^{3}$ University of Santiago de Chile (USACH), Santiago, Chile

Laboratory of Physical Activity, Sports and Health Sciences, Faculty of Medical Sciences

\begin{abstract}
Objectives: The objective of this study was to determine the effects of 2 physical exercise programs carried out during working hours in an office work environment on health-related parameters of employees. Material and Methods: The participants included 47 healthy office worker volunteers (aged $45 \pm 11.95$ years, $27 \%$ males) who formed 3 groups: circuit training (CT), brisk walk (BW), and control (C) groups. The interventions lasted 12 weeks with a weekly frequency of three 30-minute sessions in the middle of the workday. All employees were evaluated with a multicomponent battery test which included: anthropometric and body composition measurements, a cardiorespiratory fitness test, lipid profile, blood pressure, and mental health (depression, anxiety, and stress). Basic descriptive statistics were calculated. A repeated measures ANOVA was performed to summarize changes in the variables studied after the application of the physical exercise programs. Results: Generally, both exercise programs (CT and BW) maintained the body weight and body mass index while reducing body fat mass (a group $\times$ time interaction; $4.864 \leq \mathrm{F} \leq 6.524,0.001 \leq \mathrm{p} \leq 0.015$ ), although the CT intervention also showed relevant (inter-group) reductions in the waist-hip ratio $(\mathrm{F}=11.311, \mathrm{p}=0.007)$ and increased skeletal muscle mass $(F=15.062, p=0.003)$. Both exercise programs $(C T$ and $B W)$ improved the cardiorespiratory fitness test scores (a group $\times$ time interaction; $\mathrm{F}=18.054, \mathrm{p}<0.001)$. There were no changes in the lipid profile or blood pressure after the interventions, but there was an improvement in mental health $(4.760 \leq \mathrm{F} \leq 8.087,0.008 \leq \mathrm{p} \leq 0.037)$. Conclusions: The findings suggest that both types of programs could be implemented in the employees' daily routine in order to improve their overall health. Nevertheless, studies with larger samples are necessary before the conclusions can be generalized. Int J Occup Med Environ Health. 2021;34(1):39-51
\end{abstract}

Key words:

blood pressure, mental health, physical activity, body composition, lipid profile, cardiorespiratory fitness test

Funding: this study was supported by EIMSKIP company (grant No. 217026 entitled "Physical activity and sedentary behavior in the workplaces. Health promotion and changes to company's culture," project manager: Jose M. Saavedra).

Received: April 23, 2020. Accepted: July 30, 2020.

Corresponding author: Jose M. Saavedra, Reykjavik University, School of Social Sciences, Physical Activity, Physical Education, Sport and Health (PAPESH) Research Centre, Sports Science Department, Menntavegur 1, Nauthólsvík, 101 Reykjavík, Iceland (e-mail: saavedra@ru.is). 


\section{INTRODUCTION}

Inactivity has been on the rise in recent years, with lower demand for physical activity (PA) in the modern lifestyle. Environmental factors such as transportation, worksites, public spaces, and schools are made with comfort in mind, and have, in some ways, minimized the demand for regular PA [1]. However, there is an association between different aspects of public open spaces (proximity, size, quality) and PA [2]. It is known that the lack of PA increases the risk of various health problems such as cardiovascular diseases (CVDs), different forms of cancer, and type 2 diabetes, among others. Also, studies have reported a prospective relationship between sedentary lifestyles and premature mortality [1]. It is estimated that $9 \%$ of premature deaths in the world are directly linked to inactivity. Hence, inactivity is regarded as a risk factor similar to obesity and smoking which are the biggest risk factors for premature mortality [3].

In recent years, sedentary physiology has been deemed a legitimate field of study since leading a sedentary lifestyle can have some potential health threatening consequences [4]. There can be a significant difference in energy expenditure between sedentary behavior and those behaviors that are considered as just light intensity activities. Although often confused as being the same concept, it is important to distinguish between sedentary behavior and simply not getting sufficient PA. Living a sedentary lifestyle with prolonged sitting time is related to potential added health consequences on top of those from simply not getting sufficient, moderate to vigorous, PA [1]. It is interesting to note that, even when meeting the recommendations on moderate to vigorous PA, metabolic health can still be compromised with prolonged sitting exposure.

People spend around 8 h/day, 5 days/week, at work. Sedentary behavior is, in some ways, a by-product of today's office work environment in which individuals work seated at their desks for prolonged periods each day. Office workers have been shown to spend significantly more time seated at work than outside of work; therefore, work can contribute to their sedentary lifestyle [5] with estimates of their spending approx. 70-85\% of working hours sitting [6]. Long working hours can also be a barrier to workers getting regular PA or exercise. The effects of these prolonged sitting hours can have certain consequences that are detrimental to human health in the long term [4]. Workplace PA can be important to break up these sedentary patterns.

Musculoskeletal problems should also be mentioned in regard to prolonged sedentary behavior and inactivity in the work environment of general workers as much as of specific workers, like nurses [7] or warehouse staff [8]. For office workers, one of the biggest reasons for absenteeism is low back pain, and exercise interventions have been shown to be effective in reducing this problem [9]. In some cases, exercise can also help improve job performance, partly due to improvements in such psychological aspects as mood and job enthusiasm [10]. Also, exercise can be an important factor for social cohesion [11], and for preventing increased stress levels and potential burnout [12].

Interventions aimed at increasing PA or exercise during working hours have shown divergent results. A recent systematic review of experimental studies has found that interventions designed to increase PA reduced body weight, the body mass index (BMI), and waist circumference, but had no positive effects on the lipid profile or blood pressure levels [13]. Interventions designed to promote health (PA, nutrition, lifestyle habits) were found to be effective in reducing weight and muscular disorders, as well as improving employees' mental health [14]. However, other studies found no clear evidence of any improvement in employees' mental health when the interventions applied were based on physical exercise programs [15]. In this sense, physical exercise programs have shown improvements in pain located in specific areas of the body, such as the lower back [16], and they have managed to improve cardiorespiratory fitness and muscular endurance [17]. Similarly, they have been shown to be effective in reducing the levels of depression [18], and anxiety [19]. 


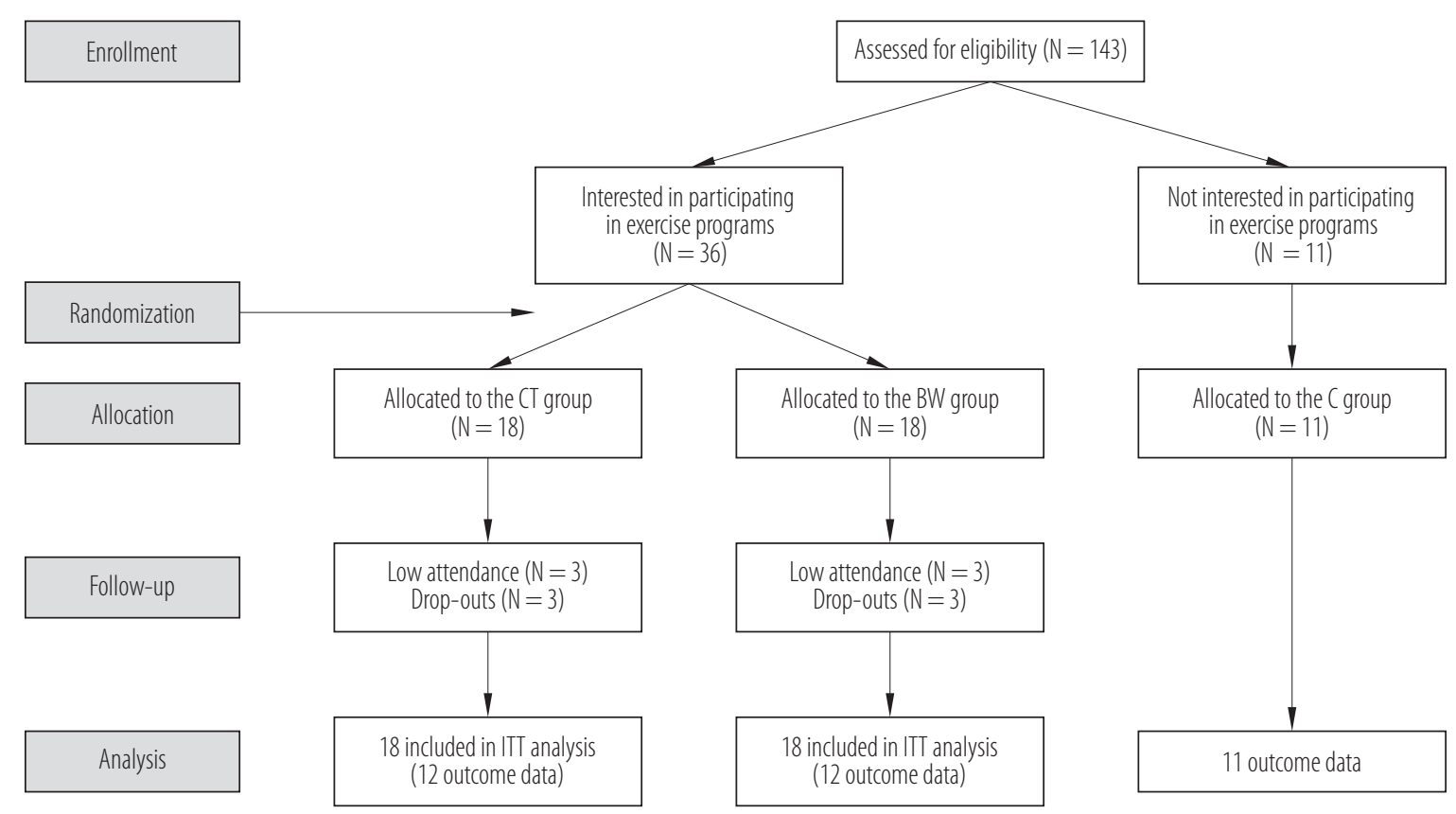

ITT - intention-to-treat.

BW - brisk walk; C - control; CT - circuit training.

Figure 1. A flowchart of the participants in the study on the effects of 2 physical exercise programs carried out during working hours in an office work environment, conducted in Reykjavik (Iceland) in February-May 2018

In this context, certain studies have been conducted regarding the use of physical exercise programs during working hours that have analyzed individually 1 or 2 healthrelated parameters (body composition, body weight, lipid profile, fitness, mental health, etc.). Therefore, the objective of this study was to take a multidimensional perspective to determine the effects of 2 physical exercise programs carried out during working hours in an office work environment on the employees' health-related parameters (anthropometry, body composition, cardiorespiratory fitness, lipid profile, blood pressure, and mental health).

\section{MATERIAL AND METHODS}

\section{Design}

This was a quasi-experimental (semi-randomized) study performed in a sedentary office work setting. The independent variable was the type of intervention (a circuit training program, a brisk walk program, or no interven- tion) performed for 12 weeks during working hours. The dependent variables were as follows: anthropometric and body composition parameters, a 6-minute walking test, lipid profile, blood pressure parameters, and mental health. All the dependent variables were evaluated immediately before and after the intervention programs.

\section{Participants}

Forty-seven healthy office worker volunteers (aged $45 \pm 11.95$ years, $27 \%$ males) participated in the study. They were divided into 3 groups:

- the circuit training group (CT) $-11 \%$ males,

- the brisk walk group (BW) - $17 \%$ males,

- the control group $(\mathrm{C})-45 \%$ males.

The participants of the first 2 groups (CT and BW) were randomly split using the IBM SPSS Statistics version 25 computer package into those groups after the baseline evaluation (Figure 1). All the participants read and signed 
Table 1. Characteristics of the sample before the interventions (baseline) and the results of Levene's test in the study on the effects of 2 physical exercise programs carried out during working hours in an office work environment, conducted in Reykjavik (Iceland) in February-May 2018

\begin{tabular}{|c|c|c|c|c|c|}
\hline \multirow{2}{*}{ Variable } & \multicolumn{3}{|c|}{$\begin{array}{l}\text { Participants } \\
\quad(\mathrm{N}=47)\end{array}$} & \multirow{2}{*}{$\mathrm{F}$} & \multirow{2}{*}{$\mathrm{p}$} \\
\hline & $\begin{array}{l}\text { CT group } \\
(\mathrm{N}=18)\end{array}$ & $\begin{array}{c}\text { BW group } \\
(\mathrm{N}=18)\end{array}$ & $\begin{array}{l}\text { C group } \\
(\mathrm{N}=11)\end{array}$ & & \\
\hline Age [years] $(\mathrm{M} \pm \mathrm{SD})$ & $44.8 \pm 15.0$ & $45.6 \pm 9.4$ & $43.2 \pm 12.1$ & 1.284 & 0.291 \\
\hline \multicolumn{6}{|c|}{ Anthropometry and body composition $(\mathrm{M} \pm \mathrm{SD})$} \\
\hline weight $[\mathrm{kg}]$ & $84.9 \pm 20.3$ & $84.4 \pm 13.6$ & $83.1 \pm 14.4$ & 0.923 & 0.408 \\
\hline $\mathrm{BMI}\left[\mathrm{kg} / \mathrm{m}^{2}\right]$ & $29.7 \pm 5.7$ & $28.6 \pm 4.1$ & $27.4 \pm 3.7$ & 1.454 & 0.250 \\
\hline WHR & $1.00 \pm 0.8$ & $0.99 \pm 0.6$ & $0.95 \pm 0.6$ & 0.476 & 0.626 \\
\hline $\mathrm{BFM}[\%]$ & $38.5 \pm 9.2$ & $35.3 \pm 9.00$ & $30.0 \pm 9.6$ & 2.395 & 0.108 \\
\hline $\operatorname{SMM}[\%]$ & $34.1 \pm 5.3$ & $35.9 \pm 5.3$ & $39.3 \pm 6.0$ & 1.463 & 0.248 \\
\hline \multicolumn{6}{|l|}{ Aerobic fitness $(\mathrm{M} \pm \mathrm{SD})$} \\
\hline 6-minute walking test [m] & $605.1 \pm 43.3$ & $624.8 \pm 32.9$ & $671.9 \pm 47.7$ & 2.994 & 0.065 \\
\hline \multicolumn{6}{|l|}{ Lipid profile [mmol/l] $(\mathrm{M} \pm \mathrm{SD})$} \\
\hline total-C & $5.6 \pm 1.2$ & $5.1 \pm 0.8$ & $5.1 \pm 0.9$ & 2.810 & 0.076 \\
\hline HDL-C & $2.0 \pm 0.6$ & $1.7 \pm 0.3$ & $1.6 \pm 0.4$ & 0.119 & 0.888 \\
\hline LDL-C & $3.3 \pm 0.9$ & $2.9 \pm 0.7$ & $2.9 \pm 0.9$ & 0.635 & 0.537 \\
\hline triglycerides & $1.8 \pm 2.1$ & $1.2 \pm 0.3$ & $1.3 \pm 0.9$ & 6.143 & 0.006 \\
\hline \multicolumn{6}{|l|}{ Blood pressure $[\mathrm{mm} \mathrm{Hg}](\mathrm{M} \pm \mathrm{SD})$} \\
\hline systolic & $123.9 \pm 11.1$ & $125.2 \pm 11.5$ & $120.8 \pm 4.6$ & 0.124 & 0.884 \\
\hline diastolic & $83.2 \pm 11.7$ & $85.4 \pm 7.3$ & $82.2 \pm 4.7$ & 2.236 & 0.129 \\
\hline \multicolumn{6}{|l|}{$\mathrm{DASS}(\mathrm{M} \pm \mathrm{SD})$} \\
\hline depression & $3.8 \pm 4.7$ & $3.1 \pm 4.3$ & $2.6 \pm 7.2$ & 0.576 & 0.568 \\
\hline anxiety & $3.4 \pm 3.1$ & $2.5 \pm 3.2$ & $2.2 \pm 2.6$ & 2.754 & 0.080 \\
\hline stress & $8.2 \pm 5.6$ & $4.8 \pm 3.3$ & $4.5 \pm 5.1$ & 3.814 & 0.054 \\
\hline total & $15.5 \pm 11.7$ & $9.9 \pm 10.1$ & $9.25 \pm 13.9$ & 2.405 & 0.108 \\
\hline
\end{tabular}

Groups: BW - brisk walk; C - control; CT - circuit training.

DASS - Depression Anxiety Stress Scales.

BFM - body fat mass; BMI - body mass index; HDL-C - high-density lipoprotein cholesterol; LDL-C - low-density lipoprotein cholesterol;

SMM - skeletal muscle mass; total-C - total cholesterol; WHR - waist-hip ratio.

an informed consent form. The study was approved by the National Bioethics Committee (Vísindasiðanefnd, ref. No. 17-226) and respected the principles of the Declaration of Helsinki. The baseline (pre-intervention) characteristics of each group are given in Table 1.

\section{Procedures}

This study was presented in an open convocation for research projects, and was subsequently funded. The researchers presented the project to a company's managers. Then, to recruit the participants, flyers and repeated 
Table 2. The number of stations, exercises, and a progression of the CT program in the study on the effects of 2 physical exercise programs carried out during working hours in an office work environment, conducted in Reykjavik (Iceland) in February-May 2018

\begin{tabular}{|c|c|c|c|}
\hline Week & $\begin{array}{l}\text { Stations } \\
{[\mathrm{n}]}\end{array}$ & $\begin{array}{l}\text { Work:Rest } \\
{[\mathrm{s}]}\end{array}$ & Exercises \\
\hline $1-2$ & 10 & $60: 30$ & $\begin{array}{l}1 \times \text { push, } 2 \times \text { pull, } 1 \times \text { knee dominant, } 1 \times \text { hip dominant, } \\
1 \times \text { specific core, } 1 \times \text { medicine ball throw, } 3 \times \text { specific aerobic }\end{array}$ \\
\hline $3-5$ & 12 & $60: 30$ & $\begin{array}{l}1 \times \text { push, } 2 \times \text { pull, } 1 \times \text { knee dominant, } 1 \times \text { hip dominant, } \\
2 \times \text { specific core, } 1 \times \text { medicine ball throw, } 4 \times \text { specific aerobic }\end{array}$ \\
\hline $6-8$ & 14 & $60: 30$ & $\begin{array}{l}1 \times \text { push, } 2 \times \text { pull, } 2 \times \text { knee dominant, } 1 \times \text { hip dominant, } \\
2 \times \text { specific core, } 1 \times \text { medicine ball throw, } 1 \times \text { arms, } 4 \times \text { specific aerobic }\end{array}$ \\
\hline $9-12$ & 16 & $60: 20$ & $\begin{array}{l}1 \times \text { push, } 2 \times \text { pull, } 2 \times \text { knee dominant, } 1 \times \text { hip dominant, } \\
2 \times \text { specific core, } 1 \times \text { medicine ball throw, } 1 \times \text { arms, } 6 \times \text { specific aerobic }\end{array}$ \\
\hline
\end{tabular}

e-mail notifications were sent out to all the office employees at the company's headquarters. The employees interested in the project had a meeting in which they were informed about the project and signed the informed consent form. Following this, the participants who were interested in the exercise intervention were randomized into 2 groups (CT and BW). The C group was recruited from those employees who had no interest in the physical exercise programs through emailing and posts on the company's Facebook page. All the participants of the 3 groups were evaluated before and after the physical exercise program (12 weeks).

\section{Interventions}

The interventions lasted 12 weeks at a frequency of 3 sessions/week, with a duration of $30 \mathrm{~min}$ in the middle of the workday. The employees who signed up to participate in the program were given an extra 15 min for their lunchtime on the training days, changing it from the standard 30-45 min. In this way, the participants could attend the 30-minute training session and get extra time for their lunch-break so that they would still be able to eat their lunch. The programs were carried out on Mondays, Wednesdays, and Fridays (the CT program at 11:30-12:00 and the BW program at 12:30-13:00). The programs were designed by the project's principal investigator following recommendations set out in the literature [20], and were taught directly by a Master's course student.

The CT intervention consisted of multiple stations with a fixed time for the exercise and for the rest between stations. Table 2 lists the number of stations, exercises, and a progression of the CT program. All the sessions started with a 5-min dynamic warm-up, and ended with a 5-minute cool-down and static stretches. The practice equipment used in the interventions consisted of resistance bands, free weights, aerobic steppers, medicine balls, bosu balls, and exercise mats.

In the BW intervention, the stride cadence objective was $>100$ strides/min throughout the walking session, i.e., the cadence recommended in the guidelines for individuals to reach moderate PA levels while walking since it is the equivalent of approximately 3 metabolic equivalents of task for most individuals [21]. The walking sessions were performed outdoors in the area around the company's headquarters. By wearing appropriate clothing, the participants were able to walk in almost all weather conditions during the study period. The weather was sometimes unfavorable, with days of snow and wind at the beginning, but the walking session was canceled only once because of bad weather. This was compensated for by adding an extra walking session on another day in the same week. 


\section{Measurements}

All the participants underwent several evaluations which included anthropometric and body composition parameters, cardiorespiratory fitness, the lipid profile, blood pressure parameters, and mental health indices.

The anthropometric and body composition measurements included height, weight, BMI, the waist-hip ratio (WHR), body fat mass (BFM), and skeletal muscle mass (SMM). The equipment used was the InBody 270 bioelectrical impedance analyzer (Hessenbergweg, Amsterdam, the Netherlands). InBody machines have been shown to have both high accuracy and test-retest reliability [22].

Cardiorespiratory fitness was evaluated with a 6-minute walking test [23]. This is a sub-maximal self-paced test which measures an individual's sub-maximal capacity to perform activities. In particular, it measures how far an individual can walk, when walking as fast as they possibly can, in a period of 6 min on a hard flat surface. In terms of the test-retest reliability, it is important that the length of the corridor and the surface type are the same. The 2 ends of the course are marked with a cone. The length of the corridor is marked every $3 \mathrm{~m}$, and the starting line is marked with a tape. The equipment needed consists of a stopwatch, cones, a tape, measurement tools, and a pen and paper to write on.

The lipid profile (total cholesterol [total-C], high-density lipoprotein cholesterol [HDL-C], low-density lipoprotein cholesterol [LDL-C], and triglycerides) and blood pressure (systolic and diastolic) were evaluated after a 12-hour fast and a 24-hour period without moderate intensity exercise. For the lipid profile testing, a nurse was contacted who came to the company offices to collect the blood samples on both the pre- and post-intervention measurement dates. After collection, the blood samples were taken directly to a laboratory in Reykjavik for analysis. The equipment used was Dimension XpandPlus (Siemens, Malvern, USA) for the lipid profile and, for the blood pressure measurements, a Visomat Comfort 20/40 blood pressure device (Visomat, Wertheim, Germany) which had been previously validated in research settings [24]. The blood pressure was evaluated twice in a seated position with an interval of 1 min between the measurements.

Finally, mental health was evaluated with the Depression Anxiety Stress Scales (DASS) questionnaire [25]. This questionnaire (42 items, 14 in each scale) evaluates the participants' levels of psychological distress in terms of depression, anxiety, and stress related symptoms. Each item asks the respondent to rate, on a score of $1-4$, the degree to which they have experienced the corresponding emotions in the past week. The score for each scale is the sum of the corresponding 14 item scores, and the total score is the sum of all 3 scales. The psychometric properties of the DASS questionnaire have been evaluated frequently. Those of the English version of the questionnaire are known to be good [25], as also are those of the version in Icelandic, the mother tongue of the participants. In the present study, the internal consistency was acceptable (Cronbach's $\alpha=0.85$ ).

\section{Statistics}

All the variables satisfied the tests of homoscedasticity (Levene's variance homogeneity test) and normality (the Kolmogorov-Smirnov test) of their distributions, except for the single case of the triglycerides in the pre-test where there was a difference between the groups (Table 1). The data were analyzed in accordance with the intentionto-treat approach [26]. Basic descriptive statistics (mean and standard deviations) were calculated. Repeated measures ANOVAs were performed to summarize changes in the dependent variables (anthropometric and body composition parameters, cardiorespiratory fitness, lipid profile, blood pressure parameters, and mental health) with respect to the independent variables (interventions: CT, $\mathrm{BW}$, and $\mathrm{C}$ ). The dependent variables were analyzed with the baseline data as co-variables. Also, the main effects of the group, time, and group $\times$ time interaction were calculated. The effect sizes of the differences were calculated as Cohen's d [27]. The statistical significance level was 
set at $\mathrm{p}<0.05$ for all analyses. For the statistical calculations, IBM SPSS Statistics version 25 was used.

\section{RESULTS}

Table 3 presents the basic descriptive statistics, the repeated measures ANOVA values, the pre- to post-intervention effectsizes, and the group, time, and their interaction effects for the studied variables. There were group $x$ time interactions in weight $(\mathrm{F}=4.864, \mathrm{p}=0.015)$, BMI $(\mathrm{F}=4.966$, $\mathrm{p}=0.014), \operatorname{BFM}(\%)(\mathrm{F}=6.524, \mathrm{p}=0.004)$, and cardiorespiratory fitness $(\mathrm{F}=18.054, \mathrm{p}<0.001)$. In the lipid profile and blood pressure, there was no group $x$ time interaction for any variable. There was only a time effect in triglycerides $(\mathrm{F}=7.387, \mathrm{p}=0.011)$. In the mental health parameters, there was no group $\times$ time interaction for any variable, although there was a time effect in all the variables $(4.760 \leq \mathrm{F} \leq 8.087 ; 0.008 \leq \mathrm{p} \leq 0.037)$.

\section{DISCUSSION}

The objective of this quasi-experimental study was to determine the effects of 2 physical exercise programs (CT and BW) carried out during working hours in an office work environment on the employees' health-related parameters (anthropometry, body composition, cardiorespiratory fitness, lipid profile, blood pressure, and mental health). To the best of the authors' knowledge, this is the first study to analyze the health effect of 2 physical exercise programs from a multidimensional perspective. In general, both programs maintained body weight and BMI during the intervention, at the same time reducing BFM and increasing cardiorespiratory fitness. Also, both groups (CT and BW) showed reduced levels of depression, anxiety, and stress, and this reduction was also present in the $\mathrm{C}$ group.

The fact that both physical exercise programs (CT and BW) maintained the values of body weight and BMI while these 2 parameters increased in the $\mathrm{C}$ group, with there being a group $\times$ time effect (Table 3 ), does not agree with previous studies which obtained reductions in these parameters, although they involved longer programs (12 months) [28] or longer sessions (40-50 $\mathrm{min}$ ) [18]. In the same line, there was also a meta-analysis of 33 studies, finding a reduction in body weight and BMI after applying physical exercise programs [13]. The CT group reduced their BFM by $3.1 \%$, and there was a group $\times$ time effect (Table 3). This seems to indicate that strength resistance work (CT) is necessary to improve this body composition parameter, which is coherent with previous studies in which programs based only on walking did not manage to reduce this parameter [29]. However, both groups, CT and BW, showed some improvements (of 8.1\% and $7.5 \%$, respectively) in the cardiorespiratory fitness test, with a group $\times$ time effect (Table 3 ). This is consistent with a recent meta-analysis that found improvements in this parameter with programs lasting 9-12 weeks [17]. Nonetheless, the same meta-analysis did not find any improvement when the programs were of 3 sessions/week, with each session lasting 16-30 min. The programs implemented in the current study lasted 12 weeks with three 30-minute sessions/week. It is noteworthy that cardiorespiratory fitness is a health-related parameter that guarantees the performance of daily activities, being a protector against illnesses such as CVDs, among others [30].

With regard to the lipid profile and blood pressure (systolic and diastolic), the implementation of the physical exercise programs did not show any improvements except for the triglycerides in the BW group (Table 4). The lipid profile results do not agree with a meta-analysis that found a reduction in the total-C and LDL-C levels after applying physical exercise programs [13], although the lengths of the sessions in those studies were longer than the 30-minute sessions as applied in the current study. With regard to blood pressure, the results seem to indicate that the physical exercise programs had no effect on those parameters, which agrees with the findings of previous studies [18,29].

Finally, with regard to mental health (depression, anxiety, stress), all the groups together (CT, BW, and C) showed im- 


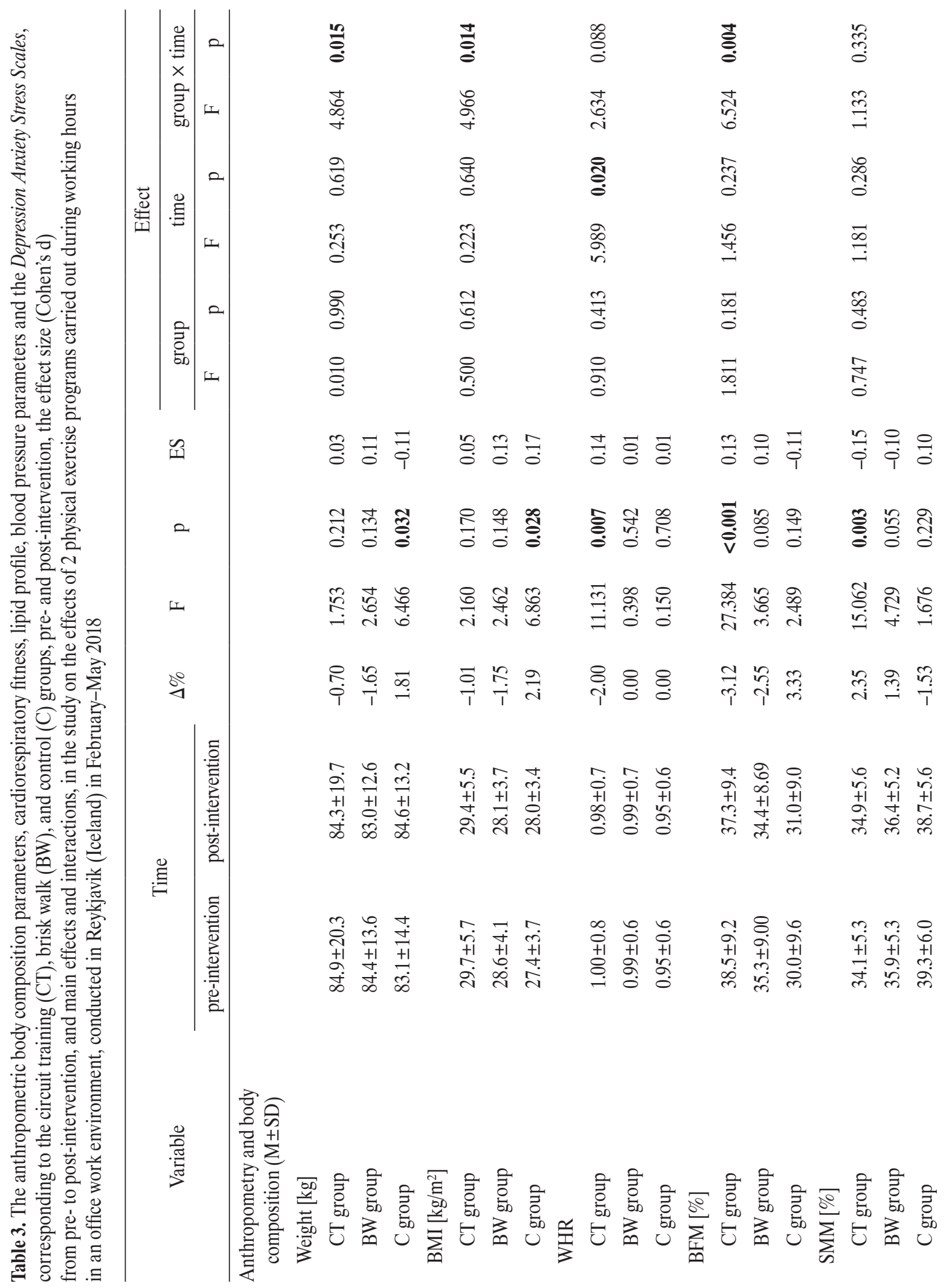




\begin{tabular}{|c|c|c|c|c|c|}
\hline$\overline{\mathrm{E}}$ & తి & 겅 & 행 & $\bar{o}$ & $\stackrel{\infty}{\circ}$ \\
\hline 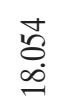 & $\stackrel{\mathscr{0}}{0}$ & 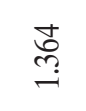 & 吕 & $\underset{i}{\stackrel{0}{0}}$ & ฮิ \\
\hline$\overline{\overrightarrow{\hat{\theta}}}$ & $\stackrel{\infty}{\stackrel{0}{0}}$ & $\stackrel{n}{\stackrel{2}{0}}$ & 志 & $\overline{\bar{s}}$ & 总 \\
\hline 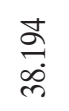 & 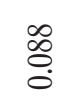 & $\stackrel{\overbrace{}}{0}$ & @્. & 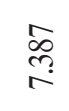 & o. \\
\hline$\stackrel{\overbrace{}}{\leftrightarrows}$ & ণ্ণ & 占 & $\stackrel{\dddot{0}}{0}$ & $\stackrel{\infty}{n}$ & $\stackrel{m}{\stackrel{0}{0}}$ \\
\hline దे & ํㅐㄱำ & $\cong$ & 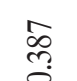 & $\tilde{6}$ & f \\
\hline
\end{tabular}

तิ

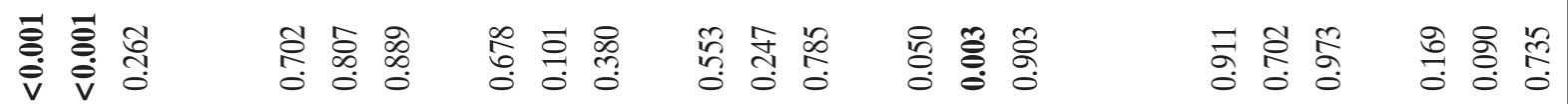

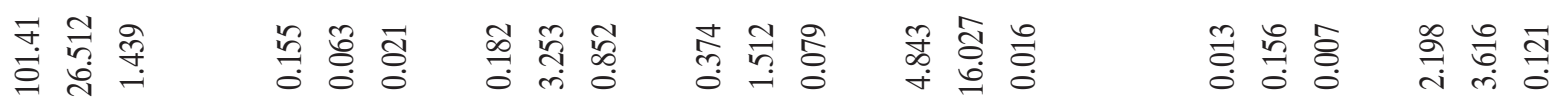

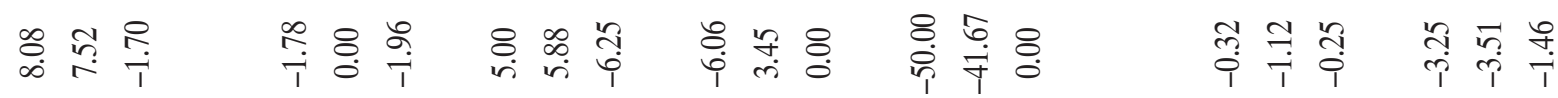

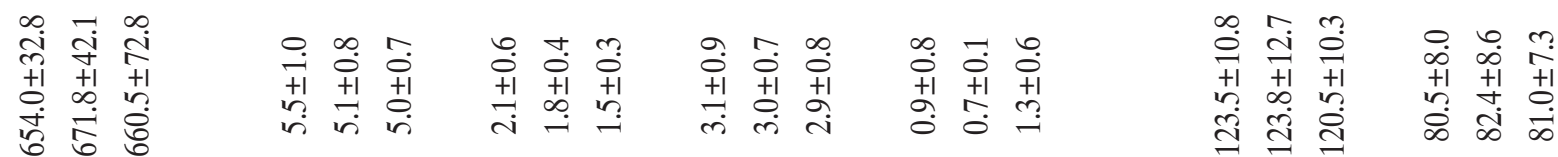

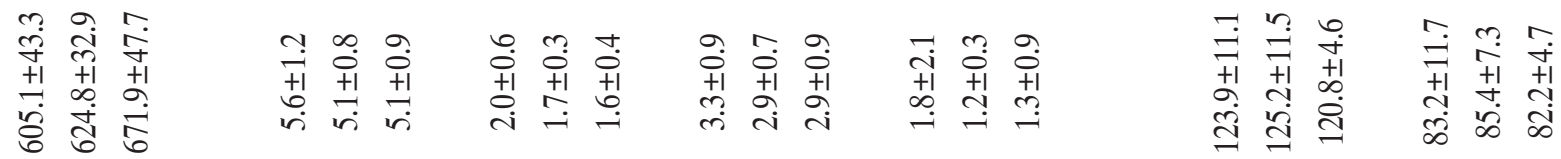

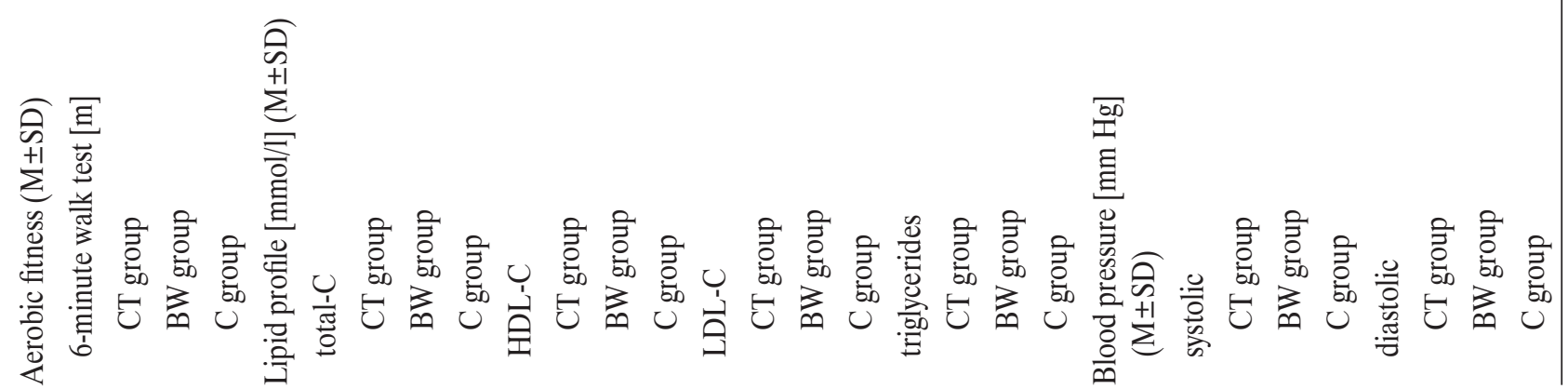




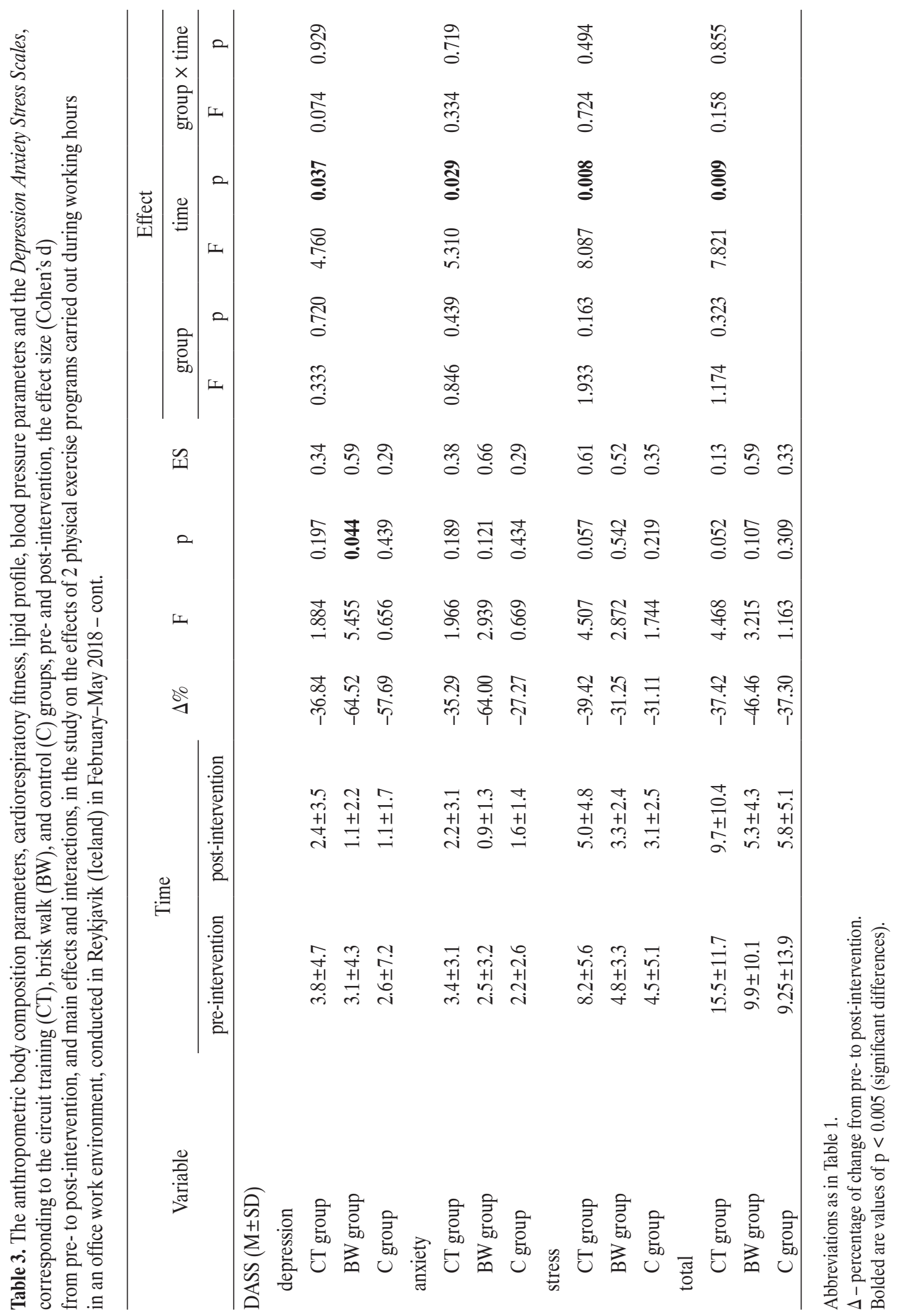


provements after the 12 weeks (a time effect), while there were only significant differences after the intervention for depression in the BW group (Table 5). The fact that a reduction in these parameters was also present in the C group appears quite surprising. The results of the present study do not agree with those of previous studies which found some differences between the aerobic physical exercise group and the control group [18]. However, a recent systematic review points to the physical exercise programs conducted during working hours having a limited effect on mental health and the psychosocial work environment [15].

The present study has several limitations. First, there was a small sample size of each of the 3 groups. However, the semi-randomization of the sample (with the 2 physical exercise groups being randomized) allowed valid conclusions to be drawn. Second, the C group was not randomized, unlike the 2 training groups. The $\mathrm{C}$ group consisted of employees who were only willing to take part in the measurements. Despite this limitation, it is worth noting that, in all the variables except one (triglycerides), there were no differences at baseline between the 3 groups (Table 1). Third, the sample was analyzed as a whole, with women being more represented than men (63\% vs. $27 \%$, respectively).

\section{CONCLUSIONS}

The conclusions drawn from the current study are as follows:

- the 2 physical exercise programs maintained body weight and BMI, although the CT intervention led to significant reductions in WHR and BFM, and to increased SMM;

- both programs considerably improved the levels of cardiorespiratory fitness;

- neither program had any effect on improving the lipid profile or blood pressure;

- both programs improved the employees' mental health, although there were similar improvements in the C group.

In general, it can be said that 30-minute physical exercise programs carried out during working hours are beneficial for various health-related parameters. This kind of a program that uses employees' lunchtime could be implemented in companies with this type of a structural timetable, thus enhancing the health of their employees. Nevertheless, studies with larger samples are necessary before the conclusions can be generalized.

\section{ACKNOWLEDGMENTS}

The authors are grateful to the managers of EIMSKIP for the facilities put at their disposal to carry out the project, and to all the participants for their involvement. The authors would also like to thank Robert A. Chatwin, Ph.D.

\section{REFERENCES}

1. Owen N, Sparling PB, Healy GN, Dunstan DW, Matthews CE. Sedentary behavior: Emerging evidence for a new health risk. Mayo Clin Proc. 2010;85(12):1138-41, https://doi.org/10.4065/ mcp.2010.0444.

2. Koohsari MJ, Mavoa S, Villanueva K, Sugiyama T, Badland H, Kaczynski AT, et al. Public open space, physical activity, urban design and public health: Concepts, methods and research agenda. Health Place. 2015;33:75-82, https://doi. org/10.1016/j.healthplace.2015.02.009.

3. Lee IM, Shiroma EJ, Lobelo F, Puska P, Blair SN, Katzmarzyk PT. Effect of physical inactivity on major non-communicable diseases worldwide: an analysis of burden of disease and life expectancy. Lancet. 2012;380:219-29, https://doi.org/ 10.1016/S0140-6736(12)61031-9.

4. Tremblay MS, Colley RC, Saunders TH, Healy GN, Owen N. Physiological and health implications of a sedentary lifestyle. Appl Physiol Nutr Metab. 2010;35(9838):725-40, https://doi. org/10.1139/H10-079.

5. Parry S, Straker L. The contribution of office work to sedentary behaviour associated risk. BMC Public Health. 2013;13:296, https://doi.org/10.1186/1471-2458-13-296.

6. Edwardson CL, Biddle SJH, Clarke-Cornwell A, Clemes S, Davies MJ, Dunstan DW, et al. A three arm cluster randomised controlled trial to test the effectiveness and cost-effectiveness 
of the SMART Work \& Life intervention for reducing daily sitting time in office workers: study protocol. BMC Public Health. 2018;18:1120, https://doi.org/10.1186/s12889-0186017-1.

7. Yao Y, Zhao S, An Z, Wang S, Li H, Lu L, et al. The associations of work style and physical exercise with the risk of work-related musculoskeletal disorders in nurses. Int $\mathrm{J}$ Occup Med Environ Health. 2019;32(1):15-24, https:/doi. org/10.13075/ijomeh.1896.01331.

8. Carvalho Mesquita C, Ribeiro JC, Moreira P. Effect of a specific exercise program on the strength and resistance levels of lumbar muscles in warehouse workers. Int J Occup Med Environ Health. 2012;25(1):80-8, https://doi.org/10.2478/s13382012-0011-0.

9. Tveito TH, Hysing M, Eriksen HR, Low back pain interventions at the workplace: a systematic literature review. Occup Med. 2004;54(1):3-13, https://doi.org/10.1093/occmed/kqg109.

10. Thøgersen-Ntoumani C, Loughren EA, Kinnafick FE, Taylor IM, Duda JL, Fox KR. Changes in work affect in response to lunchtime walking in previously physically inactive employees: A randomized trial. Scan J Med Sci Sports. 2015;25(6):778-87, https://doi.org/10.1111/sms.12398.

11. Yamamoto M, Jo H. Perceived neighborhood walkability and physical exercise: An examination of casual communication in a social process. Health Place. 2018;51:28-35, https:// doi.org/10.1016/j.healthplace.2018.02.006.

12. Bretland RJ, Thorsteinsson EB. Reducing workplace burnout: the relative benefits of cardiovascular and resistance exercise. Peer J. 2015;9:e891, https://doi.org/10.7717/peerj.891.

13. Mulchandani R, Chandrasekaran AM, Shivashankar R, Kondal D, Agrawal A, Panniyammakal J, et al. Effect of workplace physical activity interventions on the cardio-metabolic health of working adults: systematic review and meta-analysis. Int J Behav Nutr Phys Act. 2019;16:134, https://doi.org/ 10.1186/s12966-019-0896-0.

14. Proper KI, Oostrom SH. The effectiveness of workplace health promotion interventions on physical and mental health outcomes - a systematic review of reviews. Scand
J Work Environ Health. 2019;45(6):546-59, https://doi.org/ 10.5271/sjweh.3833.

15. Bordado Sköld M, Bayattork M, Andersen LL, Schlünssen V. Psychosocial effects of workplace exercise - A systematic review. Scand J Work Environ Health. 2019;45:533-45, https://doi.org/10.5271/sjweh.3832.

16. Sjögren T, Nissinen KJ, Järvenpää SK, Ojanen MT, Vanharanta H, Mälkiä EA. Effects of a workplace physical exercise intervention intensity of low back symptoms in office workers: A cluster randomized. J Back Musculoskelet Rehabil. 2005;18:1-12.

17. Prieske O, Dalager T, Herz M, Hortobagyi T, Sjøgaard G, Søgaard K, et al. Effects of physical exercise training in the workplace on physical fitness: A systematic review and meta analysis. Sports Med. 2019;49(6):1903-21, https://doi. org/10.1007/s40279-019-01179-6.

18. De Zeeuw ELEJ, Tak ECPM, Dusseldorp E, Hendriksen IJM. Workplace exercise intervention to prevent depression: A pilot randomized controlled trial. Ment Health Phys Act. 2010;3:72e77, https://doi.org/10.1016/j.mhpa.2010.09.002.

19. Atlantis E, Chow CM, Kirby A, Singh MF. An effective exercise-based intervention for improving mental health and quality of life measures: a randomized controlled trial. Prev Med. 2004;39(2):424-34, https://doi.org/10.1016/j. ypmed.2004.02.007.

20. Lawrence D, Hope B. Advanced circuit training: a complete guide to progressive planning and instructing. London: A. \& C. Black; 2008.

21. Rowe D, Welk G, Heil D, Mahar M, Kemble C, Calabro M. et al. Stride rate recommendations for moderate-intensity walking. Med Sci Sports Exerc. 2011;43(2):312-8, https:// doi.org/10.1249/MSS.0b013e3181e9d99a.

22. Ling CHY, de Craen AJM, Slagboom PE, Gunn DA, Stokkel MPM, Westendorp RGJ, et al. Accuracy of direct segmental multi-frequency bioimpedance analysis in the assessment of total body and segmental body composition in middle-aged adult population. Clin Nutr. 2011;30(5):610-5, https://doi.org/10.1016/j.clnu.2011.04.001. 
23. ATS Committee on Proficiency Standards for Clinical Pulmonary. Function Laboratories. ATS statement: guidelines for thesix-minutewalk test.AmJRespirCritCareMed.2002;166(1): 111-7, https://doi.org/10.1164/ajrccm.166.1.at1102.

24. Stergiou G, Tzamouranis D, Nasothimiou E, Protogerou A. Can an electronic device with a single cuff be accurate in a wide range of arm size? Validation of the Visomat Comfort 20/40 device for home blood pressure monitoring. J Hum Hypertens. 2008;22:796-800, https://doi.org/10.1038/jhh.2008.70.

25. Lovibond PF, Lovibond SH. The structure of negative emotional states: Comparison of the Depression Anxiety Stress Scales (DASS) with the Beck Depression and Anxiety Inventories. Behav Res Ther. 1995;33(3):335-43, https://doi. org/10.1016/0005-7967(94)00075-U.

26. Lewis JA, Machin D. Intention to treat-who should use ITT? Br J Cancer. 1993;68:647-50.

27. Cohen J. Statistical power analysis for the behavioral sciences (2nd ed.). Hillsdale (USA): Erlbaum Associates; 1988.
28. Viester L, Verhagen EALM, Bongers PM, van der Beek AJ, Effectiveness of a worksite intervention for male construction workers on dietary and physical activity behaviors, body mass index, and health outcomes: results of a randomized controlled trial. Am J Health Promot. 2018;32(3):795-805, https://doi.org/10.1177/0890117117694450.

29. Murphy MH, Murtagh EM, Boreham CA, Hare LG, Nevill AM. The effect of a worksite based walking programme on cardiovascular risk in previously sedentary civil servants [NCT00284479]. BMC Public Health. 2006;6:136, https://doi.org/10.1186/1471-2458-6-136.

30. Ross R, Blair SN, Arena R, Church TS, Després JP, Franklin BA. et al. Importance of assessing cardiorespiratory fitness in clinical practice: A case for fitness as a clinical vital sign: A scientific statement from the American Heart Association. Circ. 2016;134(24):e653-99, https://doi.org/10.1161/ CIR.0000000000000461.

This work is available in Open Access model and licensed under a Creative Commons Attribution-NonCommercial 3.0 Poland License - http://creativecommons.org/ licenses/by-nc/3.0/pl/deed.en. 